JMB AP

\title{
Dependence of $\alpha$-Synuclein Aggregate Morphology on Solution Conditions
}

\author{
Wolfgang Hoyer ${ }^{1}$, Thomas Antony ${ }^{1}$, Dmitry Cherny ${ }^{1,2}$, Gudrun Heim ${ }^{1}$ \\ Thomas M. Jovin ${ }^{1 *}$ and Vinod Subramaniam ${ }^{1 *}$
}

${ }^{1}$ Department of Molecular Biology, Max Planck Institute for Biophysical Chemistry Am Fassberg 11, D-37077 Göttingen, Germany

${ }^{2}$ Institute of Molecular Genetics Russian Academy of Sciences Kurchatov's Square, 123182 Moscow, Russian Federation
$\alpha$-Synuclein is the major component of Lewy bodies and Lewy neurites, which are granular and filamentous protein inclusions that are the defining pathological features of several neurodegenerative conditions such as Parkinson's disease. Fibrillar aggregates formed from $\alpha$-synuclein in vitro resemble brain-derived material, but the role of such aggregates in the etiology of Parkinson's disease and their relation to the toxic molecular species remain unclear. In this study, we investigated the effects of $\mathrm{pH}$ and salt concentration on the in vitro assembly of human wild-type $\alpha$-synuclein, particularly with regard to aggregation rate and aggregate morphology. Aggregates formed at $\mathrm{pH} 7.0$ and $\mathrm{pH} 6.0$ in the absence of $\mathrm{NaCl}$ and $\mathrm{MgCl}_{2}$ were fibrillar; the $\mathrm{pH} 6.0$ fibrils displayed a helical twist, as clearly evident by scanning force and electron microscopy. Incubations at $\mathrm{pH} 7.0$ remained transparent during the process of aggregation and exhibited strong thioflavin-T and weak 8-anilino-1-naphthalenesulfonate (ANS) binding; furthermore, they were efficient in seeding fibrillization of fresh solutions. In contrast, incubating $\alpha$-synuclein at low $\mathrm{pH}$ (pH 4.0 or $\mathrm{pH} 5.0)$ resulted in the rapid formation of turbid suspensions characterized by strong ANS binding, reduced thioflavin-T binding and reduced seeding efficiency. At $\mathrm{pH}$ 4.0, fibril formation was abrogated; instead, very large aggregates (dimensions $\sim 100 \mu \mathrm{m}$ ) of amorphous appearance were visible by light microscopy. As with acidic conditions, addition of $0.2 \mathrm{M} \mathrm{NaCl}$ or $10 \mathrm{mM} \mathrm{MgCl}$ to $\mathrm{pH} 7.0$ incubations led to a shorter aggregation lag time and formation of large, amorphous aggregates. These results demonstrate that the morphology of $\alpha$-synuclein aggregates is highly sensitive to solution conditions, implying that the fibrillar state does not necessarily represent the predominant or most functionally significant aggregated state under physiological conditions.

(C) 2002 Elsevier Science Ltd. All rights reserved

Keywords: $\alpha$-synuclein; thioflavin-T; protein aggregation; electron microscopy; scanning force microscopy

\section{Introduction}

The formation of $\alpha$-synuclein inclusions is a hallmark of several common neurodegenerative

Present address: V. Subramaniam, Advanced Science and Technology Laboratory, AstraZeneca R\&D Charnwood, Bakewell Road, Loughborough LE11 5RH, UK.

Abbreviations used: ANS, 8-anilino-1-naphthalenesulfonate; $C D$, circular dichorism; EM, electron microscopy; Mes, 2-(N-morpho-lino)-ethanesulfonic acid; PD, Parkinson's disease; SFM, scanning force microscopy; ThioT, thioflavin-T.

E-mail addresses of the corresponding authors: tjovin@gwdg.de; vinod.subramaniam@astrazeneca.com diseases, including Parkinson's disease (PD), dementia with Lewy bodies (DLB) and multiple system atrophy (MSA). ${ }^{1-4} \mathrm{PD}$, the most common movement disorder and the second most common neurodegenerative disorder, is clinically characterized by muscle rigidity, bradykinesia and resting tremor. The importance of $\alpha$-synuclein fibrillization in PD is supported by several observations. Insoluble $\alpha$-synuclein is the major component of Lewy bodies and Lewy neurites, cytoplasmic intraneuronal inclusions that are the defining neuropathological features of the disease. ${ }^{2,5}$ In PD, they are found predominantly in the substantia nigra of the brain, forming dense cores of filamentous and granular material. Two 
rare early-onset familial forms of PD have been linked to missense mutations (A53T and A30P) of the $\alpha$-synuclein gene, providing further evidence of the relevance of $\alpha$-synuclein for PD. ${ }^{6,7}$ This is supported by transgenic animal models of PD. Both mice and Drosophila overexpressing human $\alpha$-synuclein developed $\alpha$-synuclein immunoreactive cytoplasmic inclusions resembling Lewy bodies and exhibited motor-deficiencies. ${ }^{8,9}$ Distinct from PD and the Drosophila model, the neuronal inclusions found in transgenic mice had a granular rather than a filamentous substructure. ${ }^{8}$

$\alpha$-Synuclein is a 140 amino acid residue protein that is highly expressed in dopaminergic neurons and concentrated in the nerve terminals close to synaptic vesicles. It belongs to the group of "natively unfolded" proteins, exhibiting a random-coil secondary structure in aqueous solution. ${ }^{10}$ Three distinct regions can be identified in the $\alpha$-synuclein protein sequence. The $\mathrm{N}$-terminal part (residues 1-87) contains six imperfect 11 residue repeats with a highly conserved hexamer motif (KTKEGV), which are predicted to have a propensity for forming five amphipathic $\alpha$-helices. In fact, upon association of $\alpha$-synuclein with lipid vesicles there is a concomitant increase in $\alpha$-helical structure, ${ }^{11-14}$ prompting the suggestion that the protein plays a role in synaptic membrane biogenesis ${ }^{15}$ or the regulation of presynaptic vesicular pools. ${ }^{16}$ The central region (residues 61-95) is highly hydrophobic and includes a 12 residue stretch essential for aggregation. ${ }^{17}$ The C-terminal region (residues 96-140) is very acidic, containing ten glutamate and five aspartate residues. This domain is responsible for the natively unfolded nature of $\alpha$-synuclein, due to the combination of a large net charge and low overall hydrophobicity typical for unstructured proteins. The hydrophobicity and charge of the remaining parts of the $\alpha$-synuclein sequence are typical for folded proteins. ${ }^{18}$

Wild-type $\alpha$-synuclein, its disease-related mutants and some fragments of the wild-type protein form aggregates in vitro. ${ }^{17,19-25}$ The time-course of $\alpha$-synuclein aggregation is compatible with a nucleation-polymerization model, characterized by an initial lag phase reflecting nucleation and a subsequent growth phase culminating in a steady state. $^{26}$ The lag time and growth rate depend on the identity of the $\alpha$-synuclein mutant, ${ }^{22-25}$ the incubation conditions, e.g. $\mathrm{pH}$, temperature ${ }^{27}$ and concentration of metal ions ${ }^{28}$ or additions such as pesticides. $^{29}$ The factors leading to accelerated aggregation, such as low $\mathrm{pH}$, high temperature and metal ions, are similar inasmuch as they influence the secondary structure of the native state, giving rise to the proposal of a partially folded on-pathway intermediate in aggregation. . $7,28,30^{2}$

Structurally, the in vitro aggregates resemble material derived from disease-affected brains, i.e. they exhibit a typical amyloid-like fibrillar morphology. ${ }^{21,31}$ Apart from mature fibrils, additional morphologies have been reported for $\alpha$-synuclein aggregates. Lansbury et al. observed different kinds of small aggregates (protofibrils) and suggested that these oligomers, rather than the mature fibrils, are pathogenic. ${ }^{32,33} \mathrm{Kim}$ et al. imaged granular protein aggregates in addition to filamentous structures and reported a dependence of cytotoxicity on aggregate morphology. ${ }^{34}$ Morphological heterogeneity is characteristic for aggregates generated from many different amyloidogenic proteins..$^{35-40}$ In some cases, this structural variety is limited to the number and orientation of protofibrils in the mature fibril. In other cases, such as $\mathrm{A} \beta(1-40)^{38}$ or the immunoglobulin light chain variable domains involved in light chain amyloidosis (AL) and light chain deposition disease (LCDD), ${ }^{35}$ a dramatic shift from fibrillar to amorphous morphology occurs. These differences in the aggregated structures are highly significant in relation to the pathological consequences. For example, in the immunoglobulin light chain diseases, the nature of the aggregates is a determinant of the disease type ${ }^{35}$ and the morphology of $A \beta$ aggregates has also been correlated with the progression of Alzheimer's disease. ${ }^{38}$

Here, we describe the influence of solution conditions on the genesis and morphology of in vitro assembled wild-type $\alpha$-synuclein aggregates. Upon reduction of $\mathrm{pH}$ from 7 to 4 , aggregate morphology switches from fibrillar to amorphous. This change in aggregate structure is accompanied by an increase in hydrophobicity and a decrease in seeding efficiency. A similar change is observed upon an increase in salt concentration, giving evidence of the importance of electrostatic interactions in determining aggregate structure. The pronounced sensitivity of $\alpha$-synuclein aggregation rate and morphology to solution conditions may be of central importance for the pathology of synucleopathies.

\section{Results}

The $\mathrm{pH}$-dependence of $\alpha$-synuclein aggregation kinetics can be monitored by binding of thioflavin-T and 1-anilinonaphthalene-8sulfonic acid

The enhanced fluorescence emission of the dye thioflavin-T (ThioT) is frequently used for monitoring the kinetics of amyloid fibril formation. ${ }^{41,42} \mathrm{~A}$ second fluorescent dye exhibiting a pronounced intensity increase upon binding to amyloid fibrils is 1-anilinonaphthalene-8-sulfonic acid (ANS) ${ }^{43}$ While ThioT fluorescence is a specific marker for the $\beta$-pleated sheet conformation of amyloid structures, ANS fluoresces with high intensity when bound to hydrophobic surfaces and is thus widely used as a probe for partially unfolded protein conformations. ${ }^{4}$ Figure 1 shows kinetic traces of $\alpha$-synuclein aggregation as a function of $\mathrm{pH}$, monitored both by ThioT and ANS fluorescence. 


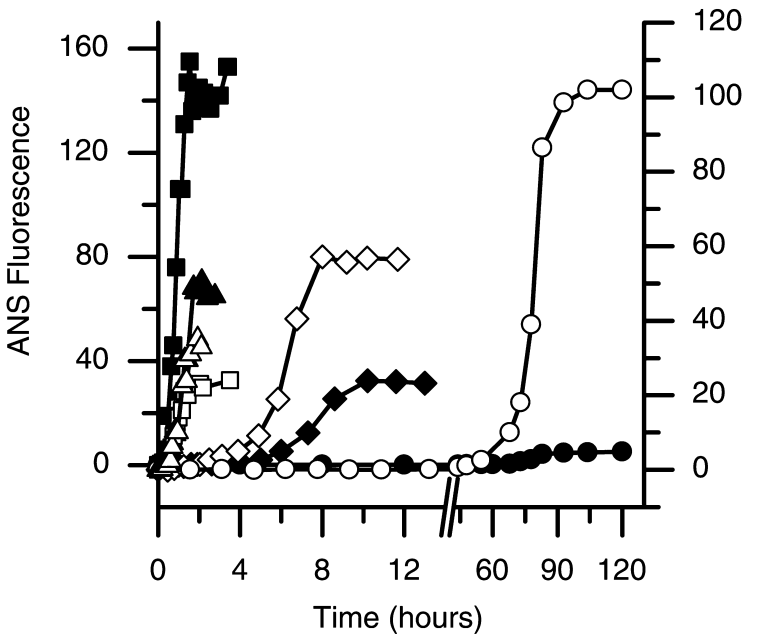

Figure 1. Kinetics of $\alpha$-synuclein aggregation at different $\mathrm{pH}$ values measured by ANS fluorescence and ThioT fluorescence. Protein solutions $(250 \mu \mathrm{M})$ were incubated at $37^{\circ} \mathrm{C}$ with constant stirring at $\mathrm{pH} 4.0$ $(\square, \mathbf{\square}), \mathrm{pH} 5.0(\triangle, \mathbf{\Lambda}), \mathrm{pH} 6.0(\diamond, \diamond)$, and $\mathrm{pH} 7.0(\bigcirc, \bullet)$. Open symbols, ThioT fluorescence (excitation $446 \mathrm{~nm}$, emission $480 \mathrm{~nm}$ ); filled symbols, ANS fluorescence (excitation $370 \mathrm{~nm}$, emission $480 \mathrm{~nm}$ ).

The sigmoidal kinetic curves observed for all $\mathrm{pH}$ values are compatible with the nucleationpolymerization process underlying amyloid formation. ${ }^{26} \mathrm{~A}$ lag phase without detectable ThioT and ANS fluorescence is followed by a growth phase in which the fluorescence intensities of the two dyes increase until a final steady state is reached. As reported by Uversky et al., $\mathrm{pH}$ has a strong influence on fibrillization kinetics. ${ }^{27}$ Decreasing the $\mathrm{pH}$ from 7.0 to 4.0 led to a decreased lag time and an increased growth rate. The incubation time required for achieving $50 \%$ of the final ThioT fluorescence signal (half-time of aggregation) was $\sim 80$ hours at $\mathrm{pH} 7.0$; it was reduced to $\sim 6.5$ hours at $\mathrm{pH} 6.0$ and to $\sim 70$ minutes at $\mathrm{pH} 5.0$ or $\mathrm{pH} 4.0$. Interestingly, the kinetic traces were similar for both fluorescent probes, demonstrating that the amyloid $\beta$-pleated sheet structure identified with ThioT fluorescence and the hydrophobic surface areas monitored by ANS fluorescence arose concurrently.

\section{Aggregates formed at different $\mathrm{pH}$ values have different spectral and morphological properties}

Samples generated at different $\mathrm{pH}$ values differed greatly in turbidity. While incubations at $\mathrm{pH}$ 7.0 remained clear, samples from $\mathrm{pH} 6.0$ to $\mathrm{pH} 4.0$ showed a dramatic increase in apparent absorption at $360 \mathrm{~nm}$, with the highest values corresponding to the lowest $\mathrm{pH}$ (Figure 2(a)). This trend was paralleled by the fluorescence intensity in ANSbinding studies (Figure 2(b)), implying that an increase in size and/or number of aggregated particles monitored by absorbance was accompanied by an increase in hydrophobic surface

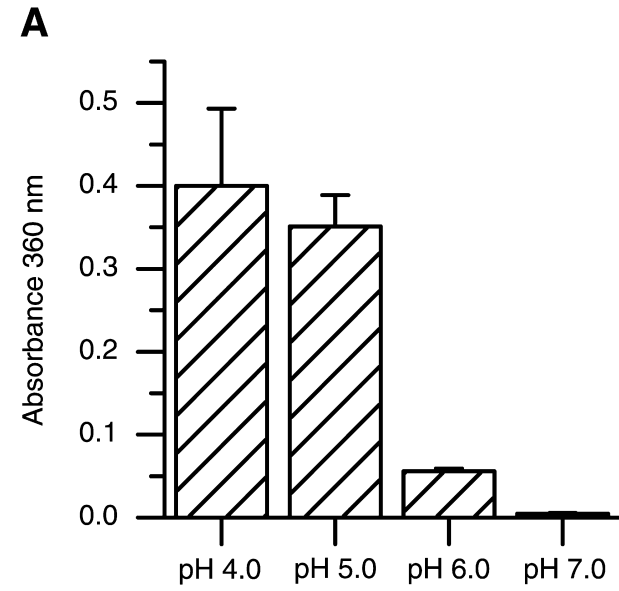

B

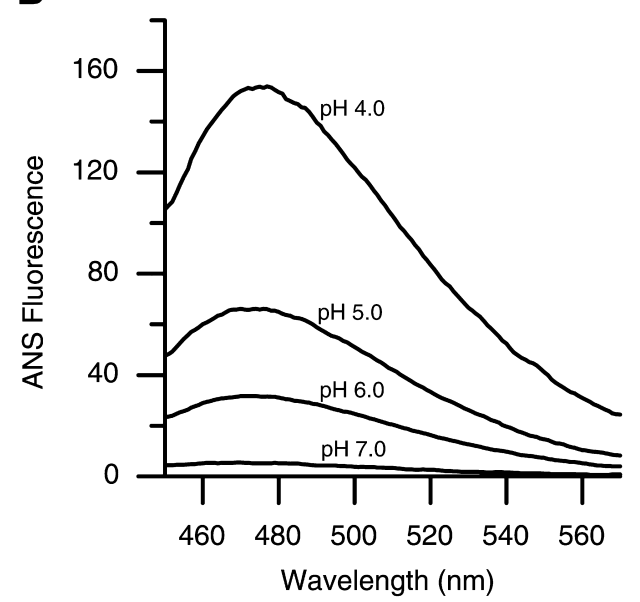

C

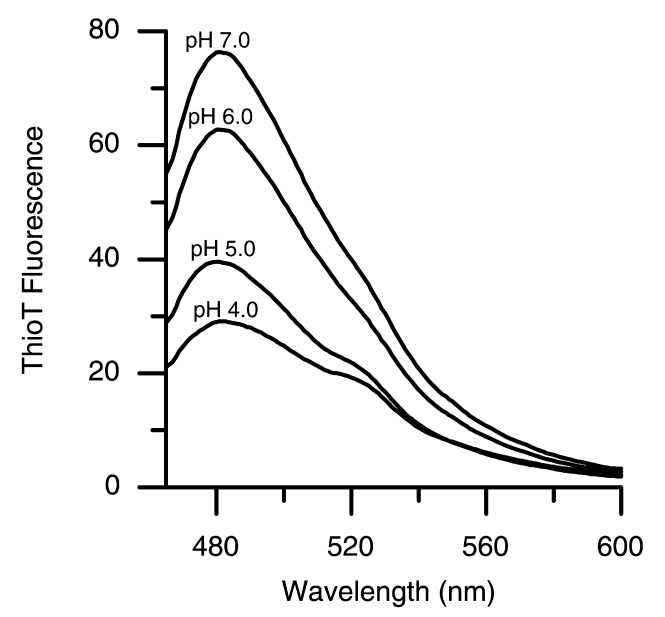

Figure 2. Effects of incubation $\mathrm{pH}$ on turbidity and dye-binding of $\alpha$-synuclein aggregates. Protein concentration, $250 \mu \mathrm{M}$; temperature, $37^{\circ} \mathrm{C}$. Aliquots were withdrawn from the different $\mathrm{pH}$ incubations after steady state was reached. (a) Turbidity $\left(A_{360}\right)$ of $\alpha$-synuclein incubations. Incubation solutions were diluted to $8.3 \mu \mathrm{M}$ in the respective buffer used in the aggregation reaction. (b) ANS emission spectra. (c) ThioT emission spectra. 


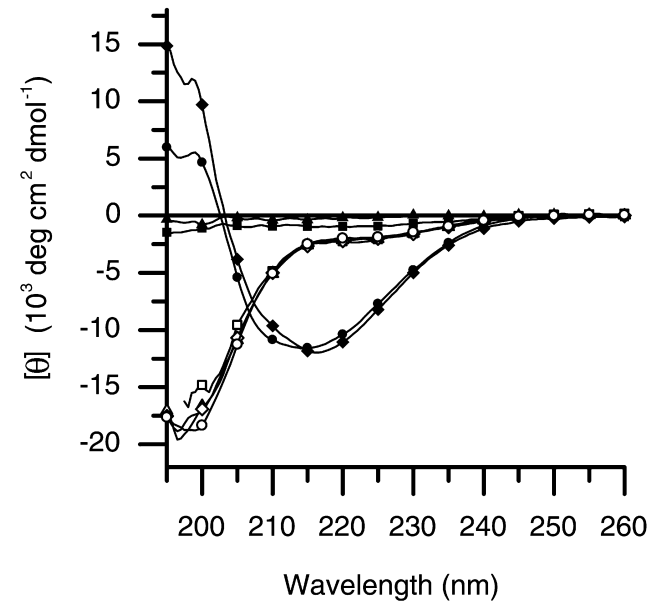

Figure 3. Far-UV CD spectra of $\alpha$-synuclein for different $\mathrm{pH}$ values. Spectra recorded before incubation (open symbols) and after steady state was achieved (filled symbols) for $\mathrm{pH} 4.0(\square, \boldsymbol{\square}), \mathrm{pH} 5.0(\triangle, \mathbf{\Lambda}), \mathrm{pH} 6.0$ $(\diamond, \diamond)$, and pH $7.0(\bigcirc, \bullet)$. Protein concentration, $250 \mu \mathrm{M}$ for incubations and $12.5 \mu \mathrm{M}$ for $\mathrm{CD}$ measurements.

area available for ANS binding. The change in aggregation mode was not associated with a complete loss of ThioT-binding potential; the latter diminished with decreasing $\mathrm{pH}$, but a substantial signal persisted at $\mathrm{pH} 4.0$ (Figure 2(c)). Formation of the ThioT-binding cross- $\beta$ amyloid structure was apparently not prevented at low $\mathrm{pH}$.

Secondary structure analysis of $\mathrm{pH} 6.0$ and $\mathrm{pH}$ 7.0 incubations by far-UV CD showed a transition from the unfolded conformation of native $\alpha$-synuclein, characterized by a minimum at $198 \mathrm{~nm}$, to a $\beta$-rich structure with a minimum at $218 \mathrm{~nm}$ (Figure 3). These CD changes were concomitant with the intensity increase in ThioT and ANS fluorescence. The far-UV spectra of $\mathrm{pH} 4.0$ and $\mathrm{pH}$ 5.0 solutions were also perturbed upon incubation but, in contrast to the higher $\mathrm{pH}$ samples, these changes were dominated by the effect of precipitation of $\alpha$-synuclein, resulting in a loss of CD

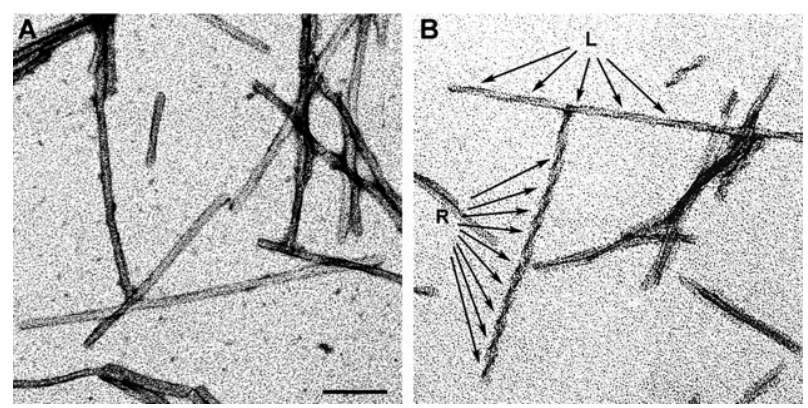

Figure 4. Electron microscopy images of $\alpha$-synuclein fibrils. Fibrils were formed at (a) $\mathrm{pH} 7.0$ and (b) $\mathrm{pH} 6.0$ at a protein concentration of $250 \mu \mathrm{M}$ and imaged after steady state was achieved. (b) Two examples of the most prominent fibril helicities at $\mathrm{pH}$ 6.0: right-handed fibrils with periodicities of $\sim 45 \mathrm{~nm}$ (labeled $\mathrm{R}$ ) and lefthanded fibrils with periodicities of $\sim 95 \mathrm{~nm}$ (labeled L). The scale bar represents $100 \mathrm{~nm}$.
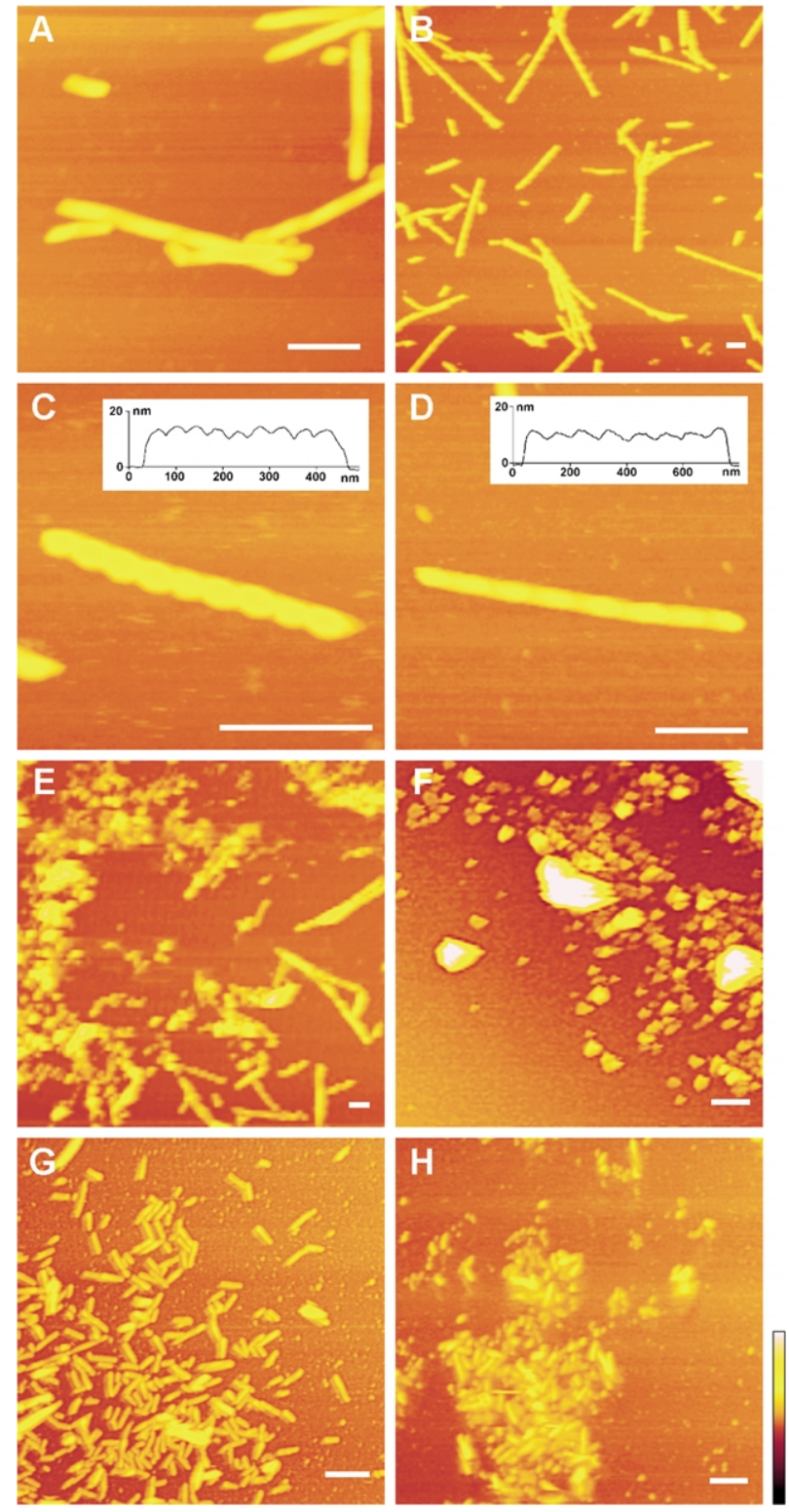

Figure 5. Scanning force microscopy images of $\alpha$-synuclein aggregates. Protein concentration, $250 \mu \mathrm{M}$. Images were taken after steady state was achieved, except for that shown in $(\mathrm{g})$, which was obtained after 20 minutes. Incubations were at (a) and (h) $\mathrm{pH} 7.0,(\mathrm{~b})-(\mathrm{d}) \mathrm{pH}$ 6.0, (e) $\mathrm{pH}$ 5.0, (f) and (g) $\mathrm{pH}$ 4.0. (c) and (d) Examples of the most prominent fibril periodicities at $\mathrm{pH} 6$. The fibril in (c) has a periodicity of $45( \pm 4) \mathrm{nm}$ and the periodicity of the fibril in (d) is $95( \pm 8) \mathrm{nm}$. Insets, height profiles of these fibrils. ( $g$ ) The image is of a sample removed from a pH 4.0 incubation after 20 minutes, which was approximately the end of the lag phase. The aggregates displayed in (h) were formed at $\mathrm{pH} 7.0$ in the presence of $10 \mathrm{mM} \mathrm{MgCl}$. The scale bar represents $200 \mathrm{~nm}$; the height bar represents $60 \mathrm{~nm}$.

signal intensity after the aggregation was completed.

The $\mathrm{pH}$ dependence of aggregate morphology was characterized further by different imaging techniques. According to both electron microscopy (EM) and scanning force microscopy (SFM) images 

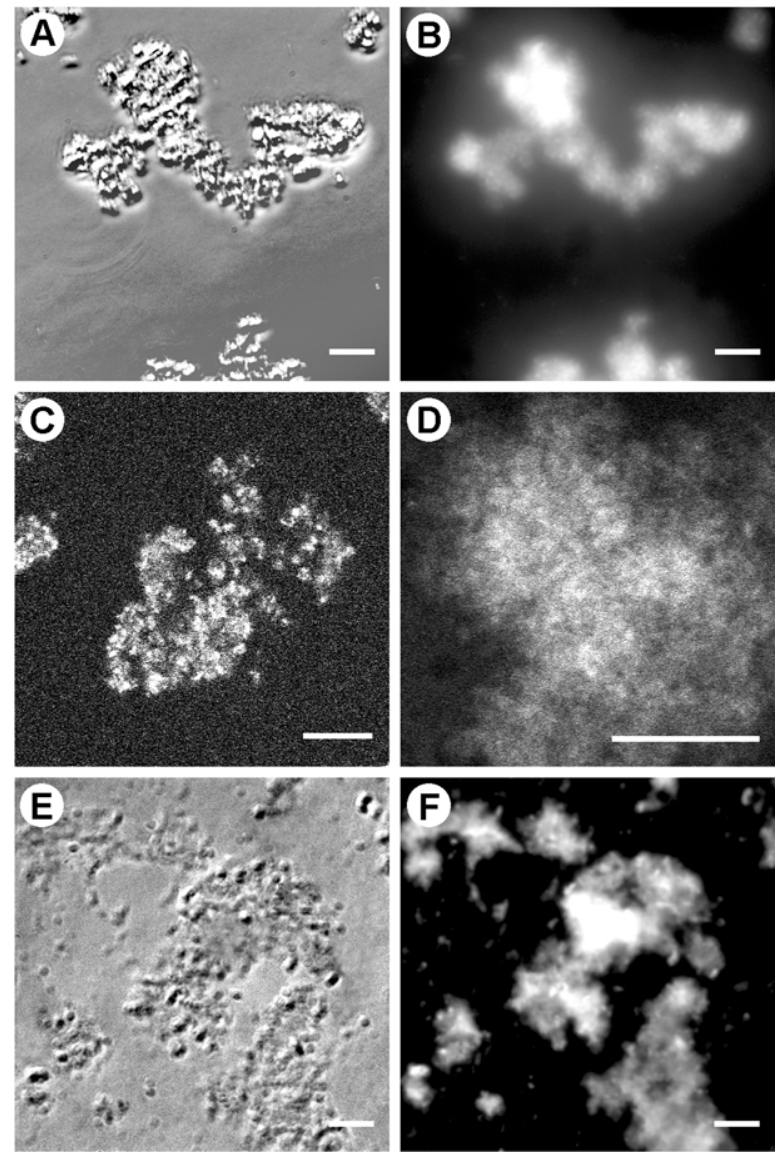

Figure 6. Bright-field and fluorescence microscopy photographs of $\alpha$-synuclein aggregates. Protein concentration, $250 \mu \mathrm{M}$. (a) Bright-field and (b) corresponding fluorescence images of aggregates formed at $\mathrm{pH}$ 4.0. Confocal fluorescence microscopy images of (c) $\mathrm{pH} 4.0$ aggregates and (d) $\mathrm{pH} 6.0$ aggregates. (e) Bright-field and (f) corresponding fluorescence images of aggregates formed at $\mathrm{pH} 7.0$ in the presence of $0.2 \mathrm{M} \mathrm{NaCl}$. The scale bar represents $20 \mu \mathrm{m}$.

of $\mathrm{pH} 6.0$ and $\mathrm{pH} 7.0$ incubations, $\alpha$-synuclein aggregates adopted a fibrillar structure (Figures $4(\mathrm{a})$ and $(\mathrm{b})$, and $5(\mathrm{a})-(\mathrm{d}))$, with fibrils of variable length $(100-1000 \mathrm{~nm}$, mean $\sim 400 \mathrm{~nm})$. The fibril diameter was $11( \pm 2) \mathrm{nm}$ from height measurements in SFM and $13( \pm 2) \mathrm{nm}$ from width measurements in EM. A consistent finding by microscopy was the untwisted nature of the fibrils formed at pH 7.0 (Figures 4(a) and 5(a)). In contrast, the majority of fibrils formed at $\mathrm{pH} 6.0$ displayed modulations in height (SFM) and width (EM) with periodicities of 40-120 nm (Figures 4(a) and $5(\mathrm{~b})-(\mathrm{d}))$. Detailed analysis of the distributions revealed clustering at $45 \mathrm{~nm}$ and $95 \mathrm{~nm}$. We infer that modulations in height and width had a common origin, i.e. a twisting of fibrils. Fibrils with twisting periods of $\sim 45 \mathrm{~nm}$ were exclusively right-handed, whereas those with twisting periods of $\sim 95 \mathrm{~nm}$ were left-handed (Figure 4(b)).

SFM images of aggregates obtained at $\mathrm{pH} 5.0$ and $\mathrm{pH} 4.0$ are shown in Figure 5(e) and (f). A large fraction of the $\alpha$-synuclein was incorporated into very large aggregates of irregular shape, which could not be subjected to a detailed surface structure analysis. However, a portion of the aggregated protein was bound to the mica as smaller particles. In the $\mathrm{pH} 5.0$ sample, these particles were generally amorphous, with the exception of some adjoining fibrils (Figure 5(e)). Such fibrillar protein aggregates were not detected at $\mathrm{pH} 4.0$ (Figure 5(f)). Instead, the material deposited on the mica was purely amorphous. However, the SFM images of $\mathrm{pH} 4.0$ incubations after 20 minutes of incubation, i.e. approximately at the beginning of the growth phase, revealed the presence of regular structural units (Figure $5(\mathrm{~g})$ ). Short fibrils with lengths of $\sim 50 \mathrm{~nm}$ and $8( \pm 2) \mathrm{nm}$ in height were observed, apparently constituting intermediate species, ultimately leading to the large, amorphous aggregates.

The EM and SFM data complemented the observations from dye-binding and turbidity measurements. Upon reducing the incubation $\mathrm{pH}$, the aggregate morphology switched from fibrillar to amorphous, with the major change occurring between $\mathrm{pH} 6.0$ and $\mathrm{pH}$ 5.0. ThioT binding, however, was not prevented at low $\mathrm{pH}$. As only minute amounts of mature fibrils were detectable at $\mathrm{pH} 5.0$ and not at all at $\mathrm{pH} 4.0$, this ThioTbinding capacity most likely originated from the surface of the large amorphous aggregates. This conclusion was confirmed by bright-field as well as by both wide-field and confocal fluorescence microscopy of aggregated solutions to which ThioT was added. $\alpha$-Synuclein incubated at $\mathrm{pH} 4.0$ and at $\mathrm{pH} 5.0$ showed large aggregates with dimensions of up to $150 \mu \mathrm{m}$ (Figure 6(a)-(c); data for $\mathrm{pH} 5.0$ not shown). The bright-field and fluorescence microscopy photographs were superimposable, corroborating the assumption that ThioT binding was distributed over the entire surface of the aggregate particles. At $\mathrm{pH} 6.0$ or $\mathrm{pH}$ 7.0, no well-defined substructure was observed. At $\mathrm{pH}$ 7.0, the ThioT fluorescence was detected as a faint background, presumably arising from uniformly distributed fibrils (data not shown), whereas the $\mathrm{pH} \quad 6.0$ samples showed diffuse spots of ThioT fluorescence attributable to large networks of $\alpha$-synuclein fibrils (Figure 6(d)).

\section{$\alpha$-Synuclein aggregates formed at $\mathrm{pH} 4$ and at pH 7 display different fibrillization seeding efficiencies}

A characteristic of amyloid protein fibrils is their potential to trigger fibril formation by seeding. Figure 7 (a) shows kinetic traces of $\alpha$-synuclein aggregation at $\mathrm{pH} 7.0$ occurring in the absence of seeds as well as in the presence of seeding with aggregates preformed at $\mathrm{pH} 4.0$ and 7.0. For the seeded incubations, $1 \%(\mathrm{v} / \mathrm{v})$ of completely aggregated solutions of the respective $\mathrm{pH}$ were added to freshly prepared protein solutions at $\mathrm{pH}$ 7.0. Aggregates of both $\mathrm{pH}$ accelerated fibrillization. However, while the $\mathrm{pH} 4.0$ seeds reduced the 
A

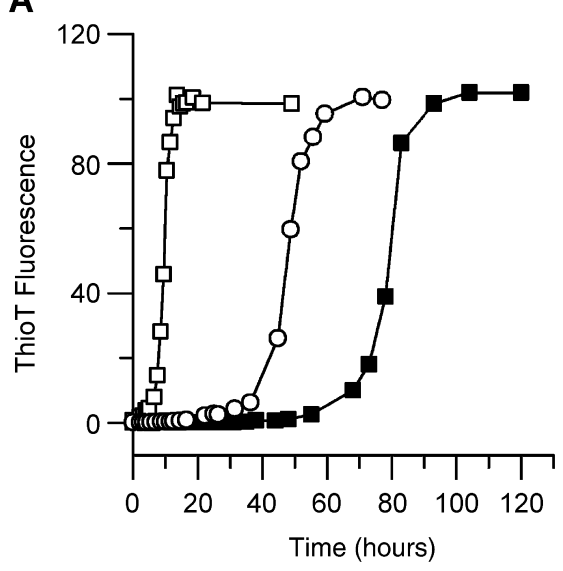

B

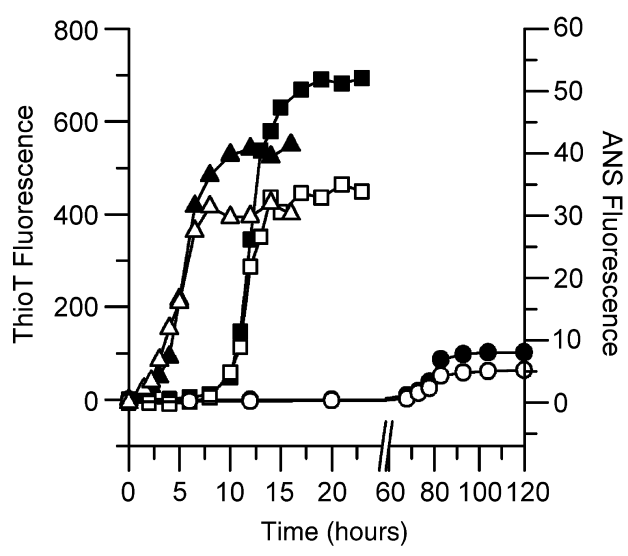

Figure 7. Effects of seeding and salt concentration on $\alpha$-synuclein aggregation kinetics. (a) Seeding efficiency of $\alpha$-synuclein aggregates formed at $\mathrm{pH} 4.0$ and $\mathrm{pH}$ 7.0. $\alpha$-Synuclein solutions ( $250 \mu \mathrm{M}, \mathrm{pH} 7.0)$ were incubated with stirring at $37^{\circ} \mathrm{C}$ without ( $\left.\square\right)$ and with previous seeding. For seeding, $1 \%(\mathrm{v} / \mathrm{v})$ of $\alpha$-synuclein aggregates formed at $\mathrm{pH} 4.0(\mathrm{O})$ and $\mathrm{pH} 7.0(\square)$ were added to the incubations. (b) Kinetics of aggregation without $(\mathrm{O}, \mathbf{0})$ and with addition of $0.2 \mathrm{M} \mathrm{NaCl}(\square, \square)$ or $10 \mathrm{mM} \mathrm{MgCl}_{2}$ $(\triangle, \mathbf{\Lambda})$. ThioT (filled symbols) and ANS measurements (open symbols) were performed as described for Figure 1.

half-time of fibrillization by only $\sim 40 \%$, addition of $\mathrm{pH} 7.0$ seeds abolished the lag phase almost completely, demonstrating the importance of fibrillar morphology for effective seeding, a feature also reported for the aggregation of amyloid peptide $\mathrm{A} \beta(1-40) .^{38}$ We conclude that $\mathrm{pH} 7.0$ incubations, but not the amorphous $\mathrm{pH} 4.0$ aggregates, contained large quantities of fibrils that could act as fibrillization nuclei.

\section{Addition of salt to $\alpha$-synuclein incubations leads to effects on aggregation rates and morphology similar to those caused by $\mathrm{pH}$ reduction}

The calculated pI of $\alpha$-synuclein is 4.7. Most of the acidic residues are concentrated in the C-terminal part of the protein, constituting 15 of the 43
C-terminal amino acid residues. Therefore, the reported effects of $\mathrm{pH}$ reduction on $\alpha$-synuclein aggregation might be mediated by the shielding of negative charges via protonation. In this case, addition of salts to $\mathrm{pH} 7.0$ incubations should affect aggregation rates and morphology, as is the case with acidification. To test this hypothesis, incubations in $10 \mathrm{mM}$ sodium phosphate $(\mathrm{pH} 7.0)$, were followed without and with addition of $0.2 \mathrm{M}$ $\mathrm{NaCl}$ or $10 \mathrm{mM} \mathrm{MgCl}$. Both salts increased the aggregation rate substantially, with $\mathrm{MgCl}_{2}$ exerting the larger effect (Figure 7(b)). The final ANS fluorescence signal was higher than that of the incubation without added salt. Moreover, the final turbidity of the aggregation solution increased dramatically from $A_{360}=0.004 \pm 0.001$ for the incubation without added salt to $0.16 \pm 0.02$ and $0.22 \pm 0.02$ for the incubations with addition of $\mathrm{NaCl}$ and $\mathrm{MgCl}_{2}$, respectively. This result was indicative of a fast formation of larger aggregates with a greater hydrophobic surface upon salt addition. Similar observations were made in incubations at low $\mathrm{pH}$.

An analysis by SFM and light microscopy of the morphology of aggregates formed in the presence of salts revealed characteristics evocative of low-pH aggregates. The SFM images of the samples incubated in $10 \mathrm{mM} \mathrm{MgCl}$ showed large aggregates composed of densely packed short fibrillar elements, reminiscent of the $\mathrm{pH} 4.0$ aggregation intermediates (Figure 5(h)). As with the low- $\mathrm{pH}$ aggregates, aggregates formed in $0.2 \mathrm{mM} \mathrm{NaCl}$ or $10 \mathrm{mM} \mathrm{MgCl}{ }_{2}$ could be imaged by transmission light microscopy, showing particle dimensions of up to $100 \mu \mathrm{m}$ (Figure 6(e)). After addition of ThioT, the aggregates were brightly fluorescent (Figure 6(f)). As with low-pH incubations, the formation of large aggregates did not prevent ThioT binding. In fact, the ThioT fluorescence of the aggregates formed in the presence of $10 \mathrm{mM} \mathrm{MgCl}$ or $0.2 \mathrm{M} \mathrm{NaCl}$ was notably higher than that of incubations in the absence of added salt (see Figure 7(b)).

\section{Discussion}

\section{Structural diversity of $\boldsymbol{\alpha}$-synuclein aggregates}

A qualitative summary of the impact of $\mathrm{pH}$ and salt conditions on $\alpha$-synuclein aggregation properties observed in this study is given in Table 1. Two major effects are evident: (i) the overall rate of aggregation is highly dependent on the solution conditions; and (ii) the aggregate morphology was altered significantly upon changes in $\mathrm{pH}$ or salt concentration.

Fibrillar aggregates dominated the $\mathrm{pH} 7.0$ and $\mathrm{pH} 6.0$ incubations. Fibrils formed at $\mathrm{pH} 7.0$ were essentially untwisted, whereas at $\mathrm{pH} 6.0$, the major fraction of fibrils showed helical modulations. Surprisingly, two opposite twisting modes were detected, right-handed with a $\sim 45 \mathrm{~nm}$ 
Table 1. Effect of ionic conditions on aggregation rate, spectral and morphological properties of $\alpha$-synuclein aggregates

\begin{tabular}{|c|c|c|c|c|c|c|}
\hline & \multirow[b]{2}{*}{$\begin{array}{l}t_{1 / 2} \\
(\mathrm{~h})^{\mathrm{a}}\end{array}$} & \multirow[b]{2}{*}{$\begin{array}{l}\text { ThioT } \\
\text { emission }\end{array}$} & \multirow[b]{2}{*}{$\begin{array}{l}\text { ANS } \\
\text { emission }^{\mathbf{b}}\end{array}$} & \multirow[b]{2}{*}{ Turbidity $^{\mathbf{b}}$} & \multicolumn{2}{|r|}{ Imaged structure } \\
\hline & & & & & EM & SFM \\
\hline pH 4.0 (50 mM sodium acetate) & $\sim 1.2$ & + & +++ & ++ & ND & \multirow{3}{*}{$\begin{array}{l}\text { Large amorphous aggregates } \\
\text { Amorphous aggregates + fibrils } \\
\text { Fibrils with periodically modu- } \\
\text { lated height }\end{array}$} \\
\hline pH 5.0 (50 mM sodium acetate) & $\sim 1.2$ & + & ++ & ++ & ND & \\
\hline pH 6.0 (20 mM Na-Mes) & $\sim 6.5$ & ++ & + & + & $\begin{array}{l}\text { Twisted } \\
\text { fibrils }\end{array}$ & \\
\hline pH 7.0 (10 mM sodium phosphate) & $\sim 80$ & ++ & $\sim 0^{c}$ & $\sim 0^{c}$ & $\begin{array}{l}\text { Regular } \\
\text { fibrils }\end{array}$ & Regular fibrils \\
\hline $\begin{array}{l}\mathrm{pH} 7.0+0.2 \mathrm{M} \mathrm{NaCl}(10 \mathrm{mM} \\
\text { sodium phosphate) }\end{array}$ & $\sim 12$ & +++ & + & & & \multirow{2}{*}{$\begin{array}{l}\text { Large aggregates displaying short } \\
\text { fibrillar elements }\end{array}$} \\
\hline $\begin{array}{l}\mathrm{pH} 7.0+10 \mathrm{mM} \mathrm{MgCl} \\
\text { sodium phosphate })\end{array}$ & $\sim 5.5$ & +++ & + & ++ & & \\
\hline \multicolumn{7}{|c|}{$\begin{array}{l}\text { ND, not detectable. } \\
\text { a Half-time of aggregation: incubation time required for the aggregation of } 50 \% \text { of protein as observed by ThioT/ANS assay. } \\
\text { b Semi-quantitative comparison of fluorescence intensities and } A_{360} \text {, respectively. } \\
\text { c Very weak signal. }\end{array}$} \\
\hline
\end{tabular}

periodicity and left-handed with a $\sim 95 \mathrm{~nm}$ periodicity. Moreover, $\mathrm{pH} 6.0$ fibrils had a higher tendency to associate, resulting in large fibril networks that were detected by fluorescence microscopy as diffuse spots. We speculate that formation of these fibril networks was the cause of the increased turbidity. The effects of decreasing the incubation $\mathrm{pH}$ from 7.0 to 6.0 demonstrate that changes in solution conditions influenced both the internal fibril structure, which is reflected in a difference in the tendency to form helical fibrils, and the interfibrillar association, which is reflected in a difference in the propensity to form fibril networks.

Further reduction to $\mathrm{pH} 5.0$ and ultimately $\mathrm{pH}$ 4.0 resulted in even more extensive effects on aggregate morphology. At $\mathrm{pH} 4.0$, no ordered fibrils were detected by SFM. Instead, the aggregates had an amorphous appearance, a relatively hydrophobic surface, and were larger, resulting in high turbidity. They could be imaged readily by bright-field microscopy. These structural alterations cannot be interpreted simply as an extrapolation of the effects of intra- and interfibrillar structure resulting from $\mathrm{pH}$ reduction from 7.0 to 6.0. Instead, earlier steps on the aggregation pathway must have been involved, as formation of mature fibrils is completely abrogated.

As with acidic conditions, the addition of $0.2 \mathrm{M}$ $\mathrm{NaCl}$ or $10 \mathrm{mM} \mathrm{MgCl}_{2}$ to $\mathrm{pH} 7.0$ incubations resulted in turbid suspensions containing large aggregates visible by light microscopy. In contrast to $\mathrm{pH} 4.0$ and $\mathrm{pH} 5.0$, aggregates formed under these conditions exhibited elements of ordered structure on their surface perceptible by SFM. Nonetheless, formation of mature fibrils was restricted, demonstrating that addition of salt as well as acidification affected one or more of the crucial steps leading to fibril formation.

\section{A common nucleation event for amorphous and fibrillar aggregation}

The aggregation kinetics were affected dramatically by ionic changes in the solution. In agreement with a nucleation-polymerization process, the time traces were characterized by an initial lag phase, a subsequent growth phase and a final steady state. Decreasing the incubation $\mathrm{pH}$ from 7.0 to 5.0 or increasing the salt concentration at $\mathrm{pH} 7.0$ resulted in a shortened lag time and an increased growth rate. The aggregation kinetics were monitored by the two fluorescent probes ThioT and ANS as well as by CD and turbidity. The four techniques probe different sample properties, i.e. CD spectroscopy monitors secondary structure changes, turbidity is an indicator of formation of large particles, ANS-binding tracks the increase of hydrophobic surface area, and ThioT fluorescence reflects the presence of amyloid structures. Nonetheless, the time traces obtained by the four methods were similar, implying that an extensive $\beta$-structure, hydrophobic surface patches, turbidity-inducing particles and ThioTbinding amyloid structures form concurrently after a common critical nucleation event. Consequently, if separate pathways exist that lead to either amorphous aggregates, as monitored by ANS binding and turbidity, or to fibrils, as monitored by ThioT fluorescence, the branchpoint must be located after nucleation (see the scheme below). The species defining this branchpoint can be either the nucleation structure itself or a later aggregation intermediate, from which fibrils and amorphous aggregates can form directly or via further aggregation intermediates. The identity and number of aggregation intermediates on the pathway to the actual aggregates observed under steady-state conditions cannot be specified from the data presented here. The assumption of a late branchpoint on the pathway to amorphous or fibrillar aggregates is supported by the observation that the large aggregates of amorphous appearance formed at $\mathrm{pH} 4.0$ showed substantial ThioT fluorescence. The shift in fluorescence maximum to $480 \mathrm{~nm}$ and the strong increase in fluorescence intensity are diagnostic of ThioT binding to amyloid structures. ${ }^{42}$ Accordingly, the $\mathrm{pH} 4.0$ aggregates that appeared purely amorphous by SFM and 


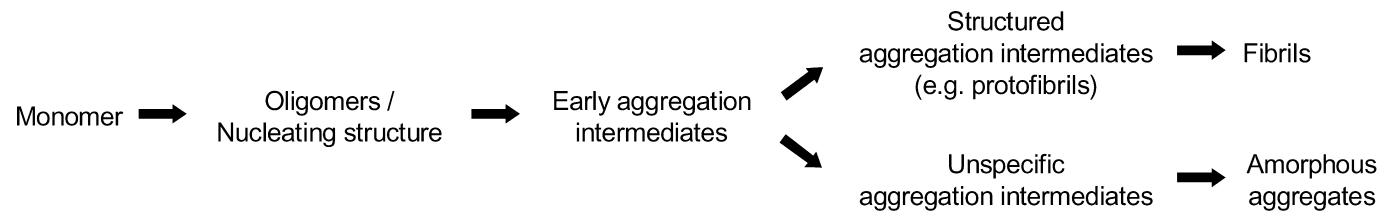

Scheme 1.

transmission light microscopy must be covered with ThioT-binding sites, i.e. they contain structural elements similar to those of the mature fibrils. We conclude that the pathways to both amorphous and fibrillar aggregates are identical in the early stages, at least up to the formation of ThioT-binding structures. In this context, the observation of early aggregation intermediates at $\mathrm{pH} 4.0$ incubations at the beginning of the growth phase was very informative. These short fibrillar particles with lengths of $\sim 50 \mathrm{~nm}$ could be suitable candidates for common intermediates on the pathway to amorphous and fibrillar aggregates, according to Scheme 1.

\section{Importance of ionic conditions for aggregate morphology}

Solution-dependencies of aggregate morphology similar to those reported here for $\alpha$-synuclein have been observed for other amyloid-forming peptides, such as the Alzheimer's amyloid peptide $A \beta$ $(1-40)^{38}$ and an amyloid forming $\mathrm{SH} 3$ domain. ${ }^{40}$ For $\mathrm{A} \beta(1-40)$, reducing the solvent $\mathrm{pH}$ from 7.4 to 5.8 results in faster aggregation and a switch in aggregate morphology from ordered fibrillar to amorphous appearance. The low-pH A $\beta$ (1-40) aggregates exhibited higher turbidity, reduced ThioT-binding and seeding efficiency, and could be imaged by light microscopy. We observed the same characteristics for the low-pH $\alpha$-synuclein aggregates. The calculated pI values of both $\mathrm{A} \beta$ $(1-40)$ (pI 5.5) and $\alpha$-synuclein (pI 4.7) are in the acidic region, suggesting that the changes in aggregation rate and aggregate morphology might originate from neutralization of negative charges. In $\alpha$-synuclein, acidic residues are concentrated at the $\mathrm{C}$ terminus. Ten glutamate and five aspartate residues are found among the last 43 amino acid residues. Neutralization of these charges by a decrease in $\mathrm{pH}$ leads to a major change in ionization state, leaving the $\mathrm{C}$ terminus almost uncharged at $\mathrm{pH}$ 4.0. The importance of the acidic side-chains for aggregate morphology is emphasized by the fibrillization experiments carried out in the presence of salts, which resulted in aggregate properties similar to those observed at low $\mathrm{pH}$. As in the protonation of the acidic residues, $\mathrm{Na}^{+}$and $\mathrm{Mg}^{2+}$ can neutralize the negative charges in the C-terminal part of the protein by electrostatic shielding. The divalent $\mathrm{Mg}^{2+}$ had a larger effect compared to the monovalent $\mathrm{Na}^{+}$, in agreement with the proposed shielding mechanism.
As acidification and elevated cation concentrations modulate both aggregation rate and morphology, ionic conditions influence the aggregation process in two ways. First, formation of the common aggregation nucleus postulated above is accelerated. Uversky et al. showed that reducing the solution $\mathrm{pH}$ from 7 to 3 results in formation of a partially folded intermediate linked to faster fibrillization kinetics. ${ }^{27}$ The population of such a folding intermediate with a greater tendency to oligomerize compared to the native monomer might result from charge shielding in the C-terminal domain. Second, the relative population of the two pathways leading to either fibrillar or amorphous aggregates is necessarily affected by changes in ionic conditions. Altered preferences for these pathways are most likely caused by modifications in the interactions between aggregation intermediates. Such effects might again be caused by the large charge differences in the $C$ terminus and corresponding charge variations on the surface of the aggregation intermediates. A large negative charge on the surface of such aggregation intermediates might then be connected with slow and specific annealing resulting in an ordered species, whereas an essentially uncharged particle surface would promote fast, unspecific association and, ultimately, amorphous aggregation.

The strong dependence of the morphology of $\alpha$-synuclein aggregates on the nature and concentration of salt revealed in this study is particularly interesting, inasmuch as the explored concentrations were physiologically relevant. The importance of aggregate morphology for protein deposition diseases has been demonstrated clearly for other misfolding diseases. ${ }^{35,38,39}$ Recently, it was reported that aggregates formed from nondisease-related amyloid-forming proteins are substantially cytotoxic, depending on their morphology, with granular and amorphous aggregates having a much higher potential to impair cell viability in comparison to mature fibrils. ${ }^{45}$ Thus, studies of other amyloidogenic proteins support the view that the structural diversity of $\alpha$-synuclein is a key element in the pathology of the synucleopathies.

\section{Materials and Methods}

\section{Expression and purification of $\alpha$-synuclein}

$\alpha$-Synuclein was expressed in Escherichia coli using plasmid pT7-7 encoding for the protein (courtesy of the Lansbury laboratory, Harvard Medical School, 
Cambridge, MA). Following transformation, BL21competent cells were grown in LB in the presence of ampicillin $(100 \mu \mathrm{g} / \mathrm{ml})$. Cells were induced with IPTG, cultured at $37^{\circ} \mathrm{C}$ for four hours and harvested by centrifugation in a Beckman Avanti J25 centrifuge with a JA-20 rotor at $5000 \mathrm{rpm}$ (Beckman Coulter, Fullerton, CA). The cell pellet was resuspended in $10 \mathrm{mM}$ Tris$\mathrm{HCl}$ ( $\mathrm{pH} 8.0), 1 \mathrm{mM}$ EDTA, $1 \mathrm{mM}$ PMSF and lysed by multiple freeze-thaw cycles and sonication. The cell suspension was boiled for 20 minutes and centrifuged at 13,500 rpm with a JA-20 rotor (Beckman Coulter). Streptomycin sulfate was added to the supernatant to a final concentration of $10 \mathrm{mg} / \mathrm{ml}$ and the mixture was stirred for 15 minutes at $4{ }^{\circ} \mathrm{C}$. After centrifugation at $13,500 \mathrm{rpm}$, the supernatant was collected and ammonium sulfate was added (to $0.36 \mathrm{~g} / \mathrm{ml}$ ). The solution was stirred for 30 minutes at $4{ }^{\circ} \mathrm{C}$ and centrifuged again at $13,500 \mathrm{rpm}$. The pellet was resuspended in $25 \mathrm{mM}$ Tris- $\mathrm{HCl}$ ( $\mathrm{pH} 7.7$ ), and loaded onto an HQ/M-column on a Applied Biosystems BIOCAD (Applied Biosystems, Foster City, CA) workstation. $\alpha$-Synuclein was eluted at $\sim 300 \mathrm{mM} \mathrm{NaCl}$ with a salt gradient from $0 \mathrm{mM}$ to $600 \mathrm{mM} \mathrm{NaCl}$. The pure $\alpha$-synuclein (judged by PAGE, electrospray ionization mass spectrometry (ESI-MS), and analytical gelfiltration) was dialyzed overnight against the appropriate buffer. Protein concentration was estimated from the absorbance at $275 \mathrm{~nm}$ using an extinction coefficient of $5600 \mathrm{M}^{-1} \mathrm{~cm}^{-1} \cdot{ }^{10}$

\section{In vitro $\alpha$-synuclein fibril formation}

Fibril formation was followed in $250 \mu \mathrm{M} \alpha$-synuclein solutions: $500 \mu \mathrm{l}$ of freshly prepared protein solution was incubated at $37^{\circ} \mathrm{C}$ in glass vials under constant stirring with micro stir bars. The buffers used were: $10 \mathrm{mM}$ sodium phosphate ( $\mathrm{pH} 7.0), 20 \mathrm{mM}$ Na-Mes ( $\mathrm{pH}$ 6.0), $50 \mathrm{mM}$ sodium acetate ( $\mathrm{pH} 4.0$ and 5.0). In the case of seeded incubations, $5 \mu \mathrm{l}(1 \%, \mathrm{v} / \mathrm{v})$ of $\alpha$-synuclein fibrillization samples in which the aggregation process was completed were added to the solution before incubation. Fibril formation was followed by ThioT-binding, ANS-binding, turbidity and CD (see below), using aliquots withdrawn during the course of the different incubations.

\section{Thioflavin-T binding}

Aliquots $(1.5 \mu \mathrm{l})$ were withdrawn from $\alpha$-synuclein incubations and added to $2.0 \mathrm{ml}$ of $5 \mu \mathrm{M}$ ThioT in either $50 \mathrm{mM}$ sodium/glycine, pH 8.2 (seeding and salt concentration experiments) or $50 \mathrm{mM} \mathrm{Na-Mes,} \mathrm{pH} 6.0$ (pH-dependence experiments). The final protein concentration was $0.19 \mu \mathrm{M}$. Fluorescence measurements were carried out on a Cary Eclipse spectrofluorimeter using $3.5 \mathrm{ml}$ quartz cuvettes (Hellma, Müllheim, Germany) with a $1 \mathrm{~cm}$ light-path. Fluorescence emission spectra were recorded from 465 to $600 \mathrm{~nm}$, using excitation at $446 \mathrm{~nm}$, an integration time of 0.1 second, and both excitation and emission bandwidths of $10 \mathrm{~nm}$. Kinetic aggregation traces were generated from time traces of ThioT fluorescence intensity at $480 \mathrm{~nm}$ and corrected for the contribution from free ThioT.

\section{ANS binding}

Aliquots $(3 \mu \mathrm{l})$ were removed from $\alpha$-synuclein incubations and added to $50 \mu \mathrm{l}$ of a $100 \mu \mathrm{M}$ aqueous solu- tion of 1-anilinonaphthalene-8-sulfonic acid (ANS). The molar protein/ANS ratio was 1:6.7. Fluorescence measurements were carried out on a Cary Eclipse spectrofluorimeter using quartz micro cuvettes (Hellma) with a $0.3 \mathrm{~cm}$ light-path. Fluorescence emission spectra were recorded from 450 to $570 \mathrm{~nm}$, using excitation at $370 \mathrm{~nm}$, an integration time of 0.1 second, with both excitation and emission bandwidth of $5 \mathrm{~nm}$. Kinetic aggregation traces (ANS fluorescence intensity at $480 \mathrm{~nm}$ ) were corrected for the signal of free ANS.

\section{Turbidity measurements}

A portion $(5 \mu \mathrm{l})$ of the $\alpha$-synuclein incubations was added to $145 \mu \mathrm{l}$ of the same buffer used for the respective incubation (see above). The final protein concentration was $8.3 \mu \mathrm{M}$. As a measure of turbidity, the absorbance at $360 \mathrm{~nm}$ was determined in a $1 \mathrm{~cm}$ pathlength ultra-micro cuvette (Hellma) in a Uvikon 943 spectrophotometer (Kontron Instruments, Milton Keynes, UK).

\section{Circular dichroism (CD) measurements}

Far-UV CD measurements were performed on a Jasco J720 spectropolarimeter (Jasco Corporation, Tokyo, Japan) using a protein concentration of $12.5 \mu \mathrm{M}$. Spectra were recorded over the range of $195-260 \mathrm{~nm}$ in a $0.1 \mathrm{~cm}$ path-length cuvette. Five scans were averaged and corrected for the respective buffer spectrum.

\section{Electron microscopy}

An aliquot was withdrawn from the incubation mixture and placed on a glow-discharged carbon film attached to an EM grid. Carbon films, 3-4 nm thick, were pre-treated by glow-discharge in the presence of pentylamine vapor (residual pressure $\sim 150 \mathrm{mTorr}$ $(1$ Torr $\approx 133.322 \mathrm{~Pa})$, discharge current $2-3 \mathrm{~mA}$, duration of discharge 30 seconds), as described. ${ }^{46}$ The adsorption continued for one to two minutes, after which the grids were rinsed with a few drops of $2 \%(\mathrm{w} / \mathrm{v})$ aqueous uranyl acetate, blotted with filter-paper, and dried. The samples were examined with a Philips CM12 electron microscope (Philips, Eindhoven, The Netherlands). The negatives were scanned at $1200 \mathrm{dpi}$ with a DuoScan T2500 scanner (Agfa, Cologne, Germany). Measurements of the micrographs were carried out with the Windows version of NIH Image (Scion Corporation, Frederick, $\mathrm{MD)}$. For printing, images were flattened using a highpass filter with a radius of 250 pixels and subsequently adjusted for contrast/brightness using Adobe Photoshop.

\section{Scanning force microscopy}

SFM images were acquired on a Digital Instruments Nanoscope III (Digital Instruments, Santa Barbara, CA). $\alpha$-Synuclein $(2.5 \mu \mathrm{M}$ in the same buffer used for the respective incubation) was deposited onto a freshly cleaved mica surface. $\mathrm{MgCl}_{2}$ (final concentration $0.5 \mathrm{mM}$ ) was added for imaging $\alpha$-synuclein aggregates from incubations performed in the absence of magnesium. The SFM head equipped with the fluid cell was placed on top of the scanner (J-Scanner, Digital Instruments) and more protein solution was added through the fluid cell. Imaging was done in tapping mode with cantilevers (NP-S, Digital Instruments, nominal spring 
constant $0.32 \mathrm{~N} / \mathrm{m}$ ) at an oscillation frequency of $\sim 9 \mathrm{kHz}$.

\section{Transmission and fluorescence microscopy}

Aliquots $(5 \mu \mathrm{l})$ from the incubation mixture were placed on a cover slide and $1 \mu \mathrm{l}$ of an aqueous $100 \mu \mathrm{M}$ ThioT solution was added. For wide-field imaging in transmission and fluorescence modes, samples were examined with a Zeiss Axiovert S100 fluorescence microscope at a magnification of $40 \times$ (Zeiss, Jena, Germany). Fluorescence images were obtained with a 431-441 nm bandpass excitation filter, a $460 \mathrm{~nm}$ dichroic filter and a 460-500 nm bandpass emission filter. Confocal fluorescence images were acquired with a Zeiss LSM 310 confocal laser scanning microscope (Zeiss, Jena, Germany) with a $20 \times$ water immersion objective. Excitation was at $488 \mathrm{~nm}$ and an emission longpass filter $(>515 \mathrm{~nm})$ was used.

\section{Acknowledgements}

W.H. gratefully thanks the Stiftung StipendienFonds des Verbandes der Chemischen Industrie and the Bundesministerium für Bildung und Forschung. T.A. was supported by the Alexander von Humboldt-Stiftung.

\section{References}

1. Goedert, M. (2001). Alpha-synuclein and neurodegenerative diseases. Nature Rev. Neurosci. 2, 492-501.

2. Spillantini, M. G., Schmidt, M. L., Lee, V. M., Trojanowski, J. Q., Jakes, R. \& Goedert, M. (1997). $\alpha$-Synuclein in Lewy bodies. Nature, 388, 839-840.

3. Baba, M., Nakajo, S., Tu, P. H., Tomita, T., Nakaya, K., Lee, V. M. et al. (1998). Aggregation of alphasynuclein in Lewy bodies of sporadic Parkinson's disease and dementia with Lewy bodies. Am. J. Pathol. 152, 879-884.

4. Wakabayashi, K., Yoshimoto, M., Tsuji, S. \& Takahashi, H. (1998). $\alpha$-Synuclein immunoreactivity in glial cytoplasmic inclusions in multiple system atrophy. Neurosci. Letters, 249, 180-182.

5. Spillantini, M. G., Crowther, R. A., Jakes, R., Hasegawa, M. \& Goedert, M. (1998). $\alpha$-Synuclein in filamentous inclusions of Lewy bodies from Parkinson's disease and dementia with lewy bodies. Proc. Natl Acad. Sci. USA, 95, 6469-6473.

6. Polymeropoulos, M. H., Lavedan, C., Leroy, E., Ide, S. E., Dehejia, A., Dutra, A. et al. (1997). Mutation in the $\alpha$-synuclein gene identified in families with Parkinson's disease. Science, 276, 2045-2047.

7. Kruger, R., Kuhn, W., Muller, T., Woitalla, D., Graeber, M., Kosel, S. et al. (1998). Ala30Pro mutation in the gene encoding alpha-synuclein in Parkinson's disease. Nature Genet. 18, 106-108.

8. Masliah, E., Rockenstein, E., Veinbergs, I., Mallory, M., Hashimoto, M., Takeda, A. et al. (2000). Dopaminergic loss and inclusion body formation in $\alpha$-synuclein mice: implications for neurodegenerative disorders. Science, 287, 1265-1269.
9. Feany, M. B. \& Bender, W. W. (2000). A Drosophila model of Parkinson's disease. Nature, 404, 394-398.

10. Weinreb, P. H., Zhen, W., Poon, A. W., Conway, K. A. \& Lansbury, P. T., Jr (1996). NACP, a protein implicated in Alzheimer's disease and learning, is natively unfolded. Biochemistry, 35, 13709-13715.

11. Davidson, W. S., Jonas, A., Clayton, D. F. \& George, J. M. (1998). Stabilization of $\alpha$-synuclein secondary structure upon binding to synthetic membranes. J. Biol. Chem. 273, 9443-9449.

12. Jensen, P. H., Nielsen, M. S., Jakes, R., Dotti, C. G. \& Goedert, M. (1998). Binding of $\alpha$-synuclein to brain vesicles is abolished by familial Parkinson's disease mutation. J. Biol. Chem. 273, 26292-26294.

13. Jo, E., McLaurin, J., Yip, C. M., St George-Hyslop, P. \& Fraser, P. E. (2000). $\alpha$-Synuclein membrane interactions and lipid specificity. J. Biol. Chem. 275, 34328-34334.

14. Narayanan, V. \& Scarlata, S. (2001). Membrane binding and self-association of $\alpha$-synucleins. Biochemistry, 40, 9927-9934.

15. Clayton, D. F. \& George, J. M. (1999). Synucleins in synaptic plasticity and neurodegenerative disorders. J. Neurosci. Res. 58, 120-129.

16. Murphy, D. D., Rueter, S. M., Trojanowski, J. Q. \& Lee, V. M. (2000). Synucleins are developmentally expressed, and $\alpha$-synuclein regulates the size of the presynaptic vesicular pool in primary hippocampal neurons. J. Neurosci. 20, 3214-3220.

17. Giasson, B. I., Murray, I. V., Trojanowski, J. Q. \& Lee, V. M. (2001). A hydrophobic stretch of 12 amino acid residues in the middle of $\alpha$-synuclein is essential for filament assembly. J. Biol. Chem. 276, 2380-2386.

18. Uversky, V. N., Gillespie, J. R. \& Fink, A. L. (2000). Why are "natively unfolded" proteins unstructured under physiologic conditions? Proteins: Struct. Funct. Genet. 41, 415-427.

19. Giasson, B. I., Uryu, K., Trojanowski, J. Q. \& Lee, V. M. (1999). Mutant and wild type human $\alpha$-synucleins assemble into elongated filaments with distinct morphologies in vitro. J. Biol. Chem. 274, 7619-7622.

20. Crowther, R. A., Jakes, R., Spillantini, M. G. \& Goedert, M. (1998). Synthetic filaments assembled from C-terminally truncated $\alpha$-synuclein. FEBS Letters, 436, 309-312.

21. Serpell, L. C., Berriman, J., Jakes, R., Goedert, M. \& Crowther, R. A. (2000). Fiber diffraction of synthetic $\alpha$-synuclein filaments shows amyloid-like cross-beta conformation. Proc. Natl Acad. Sci. USA, 97, 4897-4902.

22. Conway, K. A., Lee, S. J., Rochet, J. C., Ding, T. T., Williamson, R. E. \& Lansbury, P. T., Jr (2000). Acceleration of oligomerization, not fibrillization, is a shared property of both $\alpha$-synuclein mutations linked to early-onset Parkinson's disease: implications for pathogenesis and therapy. Proc. Natl Acad. Sci. USA, 97, 571-576.

23. Narhi, L., Wood, S. J., Steavenson, S., Jiang, Y., Wu, G. M., Anafi, D. et al. (1999). Both familial Parkinson's disease mutations accelerate $\alpha$-synuclein aggregation. J. Biol. Chem. 274, 9843-9846.

24. El-Agnaf, O. M., Jakes, R., Curran, M. D. \& Wallace, A. (1998). Effects of the mutations Ala30 to Pro and Ala53 to Thr on the physical and morphological properties of $\alpha$-synuclein protein implicated in Parkinson's disease. FEBS Letters, 440, 67-70. 
25. Li, J., Uversky, V. N. \& Fink, A. L. (2001). Effect of familial Parkinson's disease point mutations A30P and A53T on the structural properties, aggregation, and fibrillation of human $\alpha$-synuclein. Biochemistry, 40, 11604-11613.

26. Wood, S. J., Wypych, J., Steavenson, S., Louis, J. C., Citron, M. \& Biere, A. L. (1999). $\alpha$-Synuclein fibrillogenesis is nucleation-dependent. Implications for the pathogenesis of Parkinson's disease. J. Biol. Chem. 274, 19509-19512.

27. Uversky, V. N., Li, J. \& Fink, A. L. (2001). Evidence for a partially folded intermediate in $\alpha$-synuclein fibril formation. J. Biol. Chem. 276, 10737-10744.

28. Uversky, V. N., Li, J. \& Fink, A. L. (2001). Metaltriggered structural transformations, aggregation, and fibrillation of human $\alpha$-synuclein. A possible molecular link between Parkinson's disease and heavy metal exposure. J. Biol. Chem. 276, 44284-44296.

29. Uversky, V. N., Li, J. \& Fink, A. L. (2001). Pesticides directly accelerate the rate of $\alpha$-synuclein fibril formation: a possible factor in Parkinson's disease. FEBS Letters, 500, 105-108.

30. Uversky, V. N., Lee, H. J., Li, J., Fink, A. L. \& Lee, S. J. (2001). Stabilization of partially folded conformation during $\alpha$-synuclein oligomerization in both purified and cytosolic preparations. J. Biol. Chem. 276, 43495-43498.

31. Conway, K. A., Harper, J. D. \& Lansbury, P. T., Jr (2000). Fibrils formed in vitro from $\alpha$-synuclein and two mutant forms linked to Parkinson's disease are typical amyloid. Biochemistry, 39, 2552-2563.

32. Lansbury, P. T., Jr (1999). Evolution of amyloid: what normal protein folding may tell us about fibrillogenesis and disease. Proc. Natl Acad. Sci. USA, 96, 3342-3344.

33. Goldberg, M. S. \& Lansbury, P. T., Jr (2000). Is there a cause-and-effect relationship between $\alpha$-synuclein fibrillization and Parkinson's disease? Nature Cell Biol. 2, E115-E119.

34. Kim, Y. S., Lee, D., Lee, E. K., Sung, J. Y., Chung, K. C., Kim, J. \& Paik, S. R. (2001). Multiple ligand interaction of $\alpha$-synuclein produced various forms of protein aggregates in the presence of A $325-35$, copper, and eosin. Brain Res. 908, 93-98.

35. Buxbaum, J. (1992). Mechanisms of disease: monoclonal immunoglobulin deposition. Amyloidosis, light chain deposition disease, and light and heavy chain deposition disease. Hematol. Oncol. Clin. North Am. 6, 323-346.

36. Helms, L. R. \& Wetzel, R. (1996). Specificity of abnormal assembly in immunoglobulin light chain deposition disease and amyloidosis. J. Mol. Biol. 257, 77-86.

37. Khurana, R., Gillespie, J. R., Talapatra, A., Minert, L. J., Ionescu-Zanetti, C., Millett, I. \& Fink, A. L. (2001). Partially folded intermediates as critical precursors of light chain amyloid fibrils and amorphous aggregates. Biochemistry, 40, 3525-3535.

38. Wood, S. J., Maleeff, B., Hart, T. \& Wetzel, R. (1996). Physical, morphological and functional differences between $\mathrm{pH} 5.8$ and 7.4 aggregates of the Alzheimer's amyloid peptide A $\beta$. J. Mol. Biol. 256, 870-877.

39. Seilheimer, B., Bohrmann, B., Bondolfi, L., Muller, F., Stuber, D. \& Dobeli, H. (1997). The toxicity of the Alzheimer's $\beta$-amyloid peptide correlates with a distinct fiber morphology. J. Struct. Biol. 119, 59-71.

40. Zurdo, J., Guijarro, J. I., Jimenez, J. L., Saibil, H. R. \& Dobson, C. M. (2001). Dependence on solution conditions of aggregation and amyloid formation by an SH3 domain. J. Mol. Biol. 311, 325-340.

41. Naiki, H., Higuchi, K., Hosokawa, M. \& Takeda, T. (1989). Fluorometric determination of amyloid fibrils in vitro using the fluorescent dye, thioflavin $\mathrm{T} 1$. Anal. Biochem. 177, 244-249.

42. LeVine, H., III (1999). Quantification of $\beta$-sheet amyloid fibril structures with thioflavin T. Methods Enzymol. 309, 274-284.

43. Serio, T. R., Cashikar, A. G., Moslehi, J. J., Kowal, A. S. \& Lindquist, S. L. (1999). Yeast prion $[\Psi+]$ and its determinant, Sup35p. Methods Enzymol. 309, 649-673.

44. Semisotnov, G. V., Rodionova, N. A., Razgulyaev, O. I., Uversky, V. N., Gripas, A. F. \& Gilmanshin, R. I. (1991). Study of the "molten globule" intermediate state in protein folding by a hydrophobic fluorescent probe. Biopolymers, 31, 119-128.

45. Bucciantini, M., Giannoni, E., Chiti, F., Baroni, F., Formigli, L., Zurdo, J. et al. (2002). Inherent toxicity of aggregates implies a common mechanism for protein misfolding diseases. Nature, 416, 507-511.

46. Dubochet, J., Ducommun, M., Zollinger, M. \& Kellenberger, E. (1971). A new preparation method for dark-field electron microscopy of biomacromolecules. J. Ultrastruct. Res. 35, 147-167.

Edited by M. Yaniv

(Received 18 April 2002; received in revised form 22 July 2002; accepted 24 July 2002) 